\title{
Ferramenta de Autoria e Interação para apoio ao desenvolvimento de Projetos de Aprendizagem
}

\author{
Valéria Cristina Pelinzzer Cauper Monteiro ${ }^{1}$ \\ Crediné Silva de Menezes** \\ Rosane Aragón de Nevado ${ }^{* * *}$ \\ Léa da Cruz Fagundes ${ }^{* * * * *}$
}

\begin{abstract}
Resumo. O desenvolvimento de Projetos de Aprendizagem, uma prática pedagógica baseada na construção de conhecimento, desenvolvida no Laboratório de Estudos Cognitivos da UFRGS, introduzida em cursos de formação de professores para uso da informática na educação (Projeto PROINFO), vem sendo experimentada hoje em várias escolas do país. Embora esta abordagem venha sendo desenvolvida com ferramentas selecionadas dentre as existentes na Internet, entendemos que a exploração de seu potencial ainda requeira o desenvolvimento de ferramentas específicas, mais sintonizadas com sua concepção. Propomos então um ambiente integrado para desenvolvimento e acompanhamento de projetos de aprendizagem, onde estudantes, professores e outros atores possam interagir para a construção do conhecimento.
\end{abstract}

Palavras chave: Ferramentas de Autoria, Aplicações Interativas e Desenvolvimento de Projetos de Aprendizagem.

\begin{abstract}
The development of Projects of Learning, based on pedagogical practical in the construction of knowledge, developed in the Laboratory of Cognitives Studies of the UFRGS, introduced in courses of formation of professors for use of computer science in the education (Project PROINFO), comes today being tried in some schools of the country. Although this boarding comes being developed with tools selected amongst the existing ones in the Internet, we understand that the exploration of its potential still requires the development of specific tools, more syntonized with its conception. We consider then an environment integrated for development and accompaniment of learning projects, where students, professors and other actors can interact for the construction of the knowledge.
\end{abstract}

Key words: Authoring Tools, Interactive Applications and Development Projetcs of Learning.

\footnotetext{
${ }^{1}$ Mestrado em Informática (UFES). E-mail: vcpcm@yahoo.com

"* Departamento de Informática (DI-UFES), PPGIE (CINTED-UFRGS). E-mail: credine@inf.ufes.br

"*** Programa de Pós-Graduação em Educação (FACED-UFRGS). E-mail: rosane@edu.ufrgs.br

Prot* Programa de Pós-Graduação em Informática na Educação (CINTED-UFRGS). E-mail: leafagun@ufrgs.br V.3 $\mathrm{N}^{\circ} 2$, Novembro, 2005
} 


\section{Introdução}

A utilização das tecnologias da informação e da comunicação, principalmente a Internet, em situações de aprendizagem é um tema que a cada dia desperta o interesse de professores e pesquisadores. $\mathrm{O}$ tema apresenta uma crescente inserção nas agendas de pesquisa das instituições de ensino e pesquisa, no contexto nacional e internacional. $\mathrm{O}$ número de novos professores que a cada dia aproximam-se da tecnologia em busca de uma apropriação pedagógica é crescente e animador. Entretanto, como tende a ocorrer na apropriação de toda nova mídia, o que vemos hoje, na maioria experiências relatadas, é uma simples transposição de práticas pedagógicas correntes para o contexto da Internet. Segundo Nevado (2001), apesar das disposições à inovação, as indiferenciações nas condições fundamentais à mudança têm favorecido as pseudoinovações, reduzindo as novas possibilidades abertas pelo uso das tecnologias à simples otimizações das práticas tradicionais. Mostra-se premente a necessidade de produção de conhecimento, mediante pesquisas que alcancem diferenciar às condições fundamentais para a transformação do processo educativo, incluindo-se aí a pesquisa sobre novas possibilidades de aplicação do potencial interativo das ferramentas telemáticas quando essas estão servindo a uma aprendizagem contextualizada e cooperativa.

Educadores, ao longo de vários anos, vêm apresentando e aplicando novas abordagens pedagógicas que, abandonando o paradigma da transmissão do conhecimento, centram seu foco na atividade e autonomia dos aprendizes (Piaget, 1976, 1984). Portanto, é importante que se busque caminhos para dar suporte tecnológico a essas novas práticas, explorando, sempre que possível, os recursos proporcionados pela Internet.

Nas aplicações desenvolvidas para Internet encontrarmos vários exemplos de ferramentas e experiências baseadas na autoria e na interação. Dentre estas podemos citar o editor wiki e as ferramentas do tipo blog e flog. Estas ferramentas, desenvolvidas inicialmente para fins recreativos, estão sendo incorporadas por professores às suas atividades, dando suporte à novas práticas pedagógicas, rompendo assim com os ambientes convencionais, que são por concepção orientados ao ensino.

O desenvolvimento de Projetos de Aprendizagem, uma prática pedagógica baseada na construção de conhecimento, desenvolvida no Laboratório de Estudos Cognitivos (LEC) da UFRGS, introduzida em cursos de formação de professores para uso da informática na educação (Projeto PROINFO), vem sendo experimentada hoje em várias escolas do país (Fagundes, 1999). Embora esta abordagem venha sendo desenvolvida com ferramentas selecionadas dentre as existentes na Internet, entendemos que a exploração de seu potencial ainda requeira o desenvolvimento de ferramentas específicas, mais sintonizadas com sua concepção (Fagundes, 2005). Propomos então um ambiente integrado para desenvolvimento e acompanhamento de projetos de aprendizagem, onde estudantes, professores e outros atores possam interagir para a construção do conhecimento.

Este artigo apresenta a seguinte organização: a seção seguinte discute o desenvolvimento de Projetos de Aprendizagem; em seguida apresenta-se os requisitos de um ambiente para a Pedagogia de Projetos de Aprendizagem; na seção seguinte, de acordo com os requisitos discutidos, é proposto um ambiente que dê suporte ao desenvolvimento de Projetos de Aprendizagem, apresenta-se sua arquitetura e mostra-se o andamento do projeto. Por fim são tecidas as considerações finais e apresentadas as referências bibliográficas. 


\section{Desenvolvendo Projetos de Aprendizagem}

Os Projetos de Aprendizagem constituem uma arquitetura pedagógica (Carvalho, 2005) que estende a Pedagogia de Projetos, distanciando-se desta ao colocar no centro da ações o estudante.. Neste contexto, os projetos são definidos pelos estudantes, que se organizam em grupos a partir de uma livre negociação baseada em interesses e curiosidades. Os projetos são construídos coletivamente pelos estudantes com a mediação e o apoio dos professores.A sistematização desta arquitetura compreende o lançamento de problemas e formulações a partir de suas "Certezas Provisórias" e "Dúvidas Temporárias"2. Em termos de metodologia, o primeiro passo é selecionar uma indagação, uma pergunta, que para fins didáticos, denomina-se de "Questão de Investigação". A seguir é feito um inventário dos conhecimentos (sistemas nocionais, ou conceituais dos aprendizes) sobre a questão. Esse conhecimento pode ser classificado em dúvidas e certezas. As certezas para as quais não se conheça os fundamentos que a sustentem são denominadas de provisórias. As dúvidas são sempre temporárias. O processo de investigação consiste no esclarecimento das dúvidas e na validação das certezas.

Partir de uma sistematização do conhecimento já construído por um sujeito ou grupo, bem como das dúvidas relativas ao problema elegido, facilita o desenvolvimento de um trabalho originado nos sistemas de significação dos sujeitos ou grupos e em suas necessidades cognitivas de responder a determinados desafios. Desta forma, a busca e seleção de informações, a escolha dos procedimentos de testagem, a proposição de alternativas de solução e a organização e comunicação dos resultados passam a ter a relevância necessária para a construção de conhecimentos.

\section{Requisitos de um ambiente para Desenvolvimento de Projetos de Aprendizagem}

Para desenvolver seu projeto o estudante (ou o grupo) precisa publicar seus progressos, isto pode feito através da criação de um site do projeto na Internet. A publicação do site tem várias contribuições para o próprio processo. O estudante tornase produtor de conhecimento, abre-se possibilidade para que ele integre-se a uma rede de autores, ao invés de ser um mero consumidor. Para isto precisamos de ambientes de autoria específicos, concebidos para suportar o trabalho cooperativo à distância. Os professores precisam acompanhar o trabalho de seus alunos, analisar seus progressos e dar-lhes feedback que facilite a corrigir rumos ou sair de dificuldades. Os sites construídos devem então prever mecanismos que facilitem a interação professor-aluno. Os estudantes precisam discutir e tomar decisão sobre o andamento do projeto, essas discussões serão, ora síncronas ora assíncronas. O ganho com os projetos de aprendizagem pode ser exponenciado pela contribuição dos demais estudantes e outros eventuais interessados. Assim, o ambiente de autoria deve prover facilidades para que os construtores de projetos disponibilizem ferramentas de interação, que ampliem suas redes de colaboração. Para coletar dados e informações, os estudantes precisam de ferramentas especificas, tais como sites de buscas e sistemas de questionários. As máquinas de busca usuais são muito abertas, tratam da Internet com um todo, mas servem de um bom ponto de partida para a construção de ambientes mais sintonizados

2 Os termos "Certezas Provisórias" e "Dúvidas Temporárias" foram introduzidos pela Profa. Dra Léa da Cruz Fagundes durante o Curso de Especialização para Professores Multiplicadores. PROINFO/Secretaria de educação do Pará, 1998. 
com a prática de Projetos de Aprendizagem. Um sistema de coleta de dados deve prever a autoria, publicação, coleta e análise de dados.

O desenvolvimento do projeto de aprendizagem envolve várias interações e atividades para sua construção. E os produtos e informações gerados nestas atividades precisam ser interligados para que os desenvolvedores, possam, a qualquer instante acessar suas lições aprendidas, relembrando decisões, etc. Cada interação entre os usuários para a construção do projeto gera vários documentos em formas diferentes, tais como: textos, imagens, vídeos, tabelas, mapas de conceitos, gráficos, animações, apresentações, jogos, etc, estes documentos precisam ser registrados e estar acessíveis aos usuários.

Para mostrar a interação entre os "usuários" do ambiente e os documentos gerados dessas interações no desenvolvimento do projeto de aprendizagem, definimos papéis e formas de interação entre os usuários do ambiente, sendo assim, primeiramente, foram definidos os seguintes perfis: aluno (ao construir o seu conhecimento e utilizar os recursos do ambiente); professores ou monitores (no processo de acompanhamento e avaliação do aluno) e visitantes (pessoas que visitam os projetos desenvolvidos pelos alunos), outro perfil definido é o do administrador que será desempenhado por um professor. Além das atividades/tarefas desempenhadas por cada um desses perfis, foram estabelecidas as principais interações entre os pares: Aluno x Aluno, Professor x Aluno, Visitante x Grupo de Alunos (Equipe) e Professor x Professor.

Para cada uma das interações entre os perfis descreveremos algumas ferramentas de apoio necessárias para um ambiente para dar suporte a Pedagogia de Projetos de Aprendizagem. Tendo que, algumas dessas ferramentas são utilizadas em mais de um perfil ou por um par de interações, porém a visão dentro do ambiente é diferenciada. Relacionaremos as necessidades de ferramentas divididas por perfis e pares de interação, como:

\section{A. Professor x Aluno}

A interação entre professor e aluno é essencial dentro de um ambiente de suporte a Pedagogia de Projetos de Aprendizagem, para isso são necessárias algumas ferramentas como as listadas abaixo. O questionamento e discussões com o professor levam o aluno a pensar e criar seus esquemas, e assim, construir seus projetos de aprendizagem.

- Enviar Bilhetes: o professor poderá interagir com os alunos através do envio de bilhetes para os projetos, fazendo suas considerações e obtendo um feedback dos alunos.

- Visualizar projetos: o professor poderá visualizar o andamento de todos os projetos de seus alunos.

- Diário do Professor: ao avaliar um projeto, o professor poderá guardar seus comentários em seu diário e também poder lincar este comentário a algum trecho de texto que ele comentou.

- Geração de Versões: todo o processo de desenvolvimento do projeto dos alunos será armazenado e cada uma das versões poderá ser comentada pelo professor orientador.

\section{B. Alunos x Alunos}


A aprendizagem do aluno está diretamente relacionada com o seu processo cognitivo. A interação entre os alunos é uma forma de atrair e incentivá-los a utilizar as ferramentas disponíveis no ambiente e cooperarem entre si para o desenvolvimento dos projetos. Podemos citar algumas ferramentas para isso: 


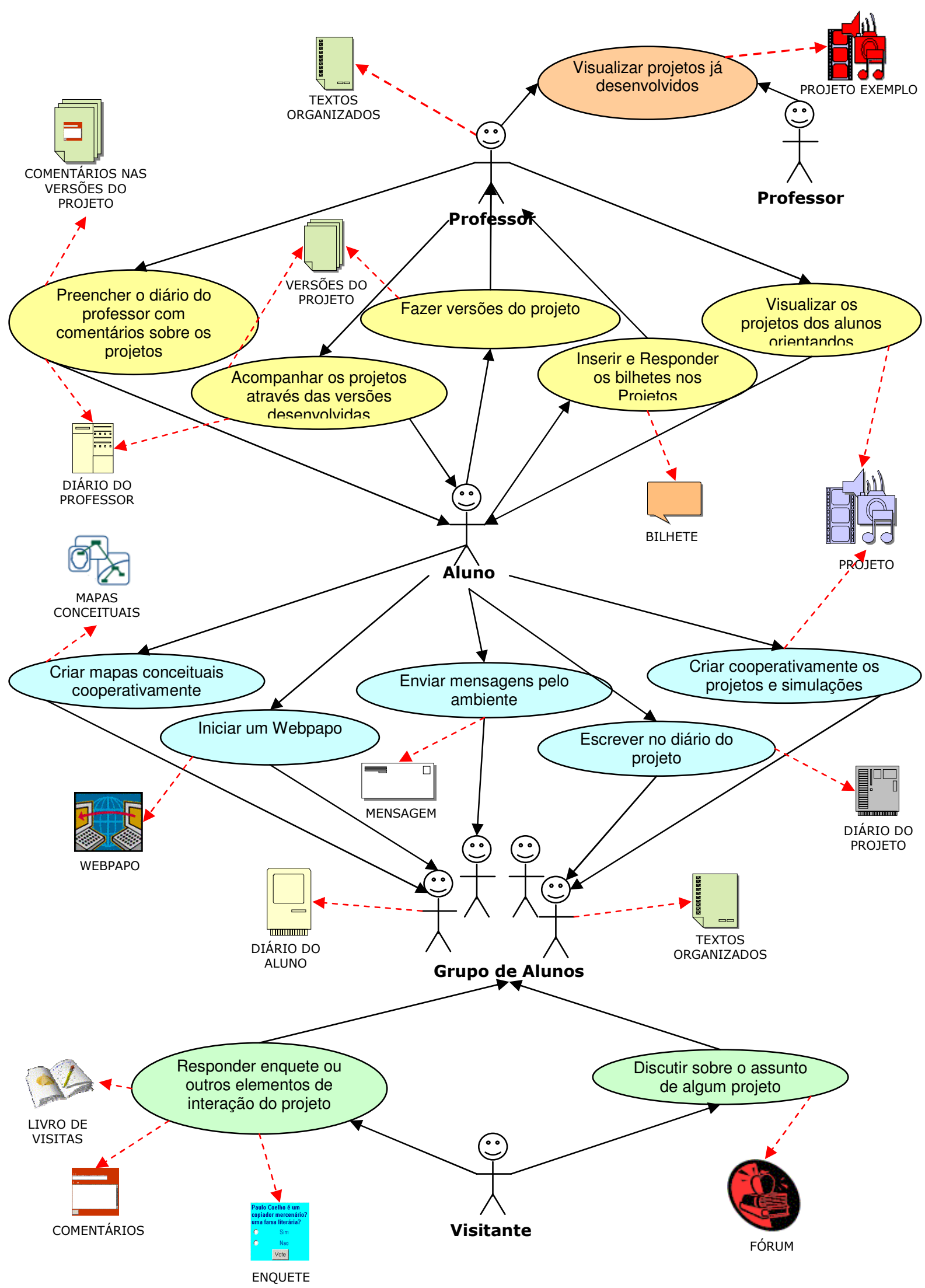

Figura 1. Interação entre os usuários do ambiente. 
- Criação e Edição de Sites: a criação colaborativa dos sites é feita com a interação dos alunos, que podem estar próximas ou distantes fisicamente.

- Diário do Projeto: durante o desenvolvimento do projeto, os alunos participantes do mesmo podem fazer suas anotações e exposição de idéias no diário do projeto.

- Upload das páginas dos alunos: os alunos poderão fazer o upload de suas páginas já desenvolvidas em outros ambientes.

- Criação de Mapas Conceituais: os alunos e professores poderão construir seus mapas conceituais e integra-los ao site construído.

- Criação de Enquete: a enquete pode ser criada pelos alunos, para que os mesmos possam interagir com visitantes dos seus sites.

- Criação de Fóruns: o aluno pode querer agregar um fórum ao seu tema de investigação do projeto, aumentando a interação entre alunos e visitantes.

- Simulações: framework para a construção de simuladores, tais como: leis da física, sistema de engrenagens e etc. E, que seja possível integrar os mapas conceituais e confecção de gráficos.

- Webpapo: quando os alunos estão online no ambiente eles podem se comunicar através do webpapo, onde todos poderão comentar e conversar o que estão fazendo.

\section{Visitante x Grupo de alunos}

A interação dos alunos e visitantes é uma forma de feedback para os projetos desenvolvidos. Esta interação pode ocorrer através das ferramentas:

- Ferramentas de discussão no projeto: os visitantes podem participar dos projetos dos alunos dando-lhes um feedback através de comentários, forúm, livro de visitas e discussão associada a um projeto.

- Responder Enquete: os visitantes poderão responder as enquetes colocadas nos projetos, de acordo com as questões descritas pelos alunos.

\section{Ambiente Proposto}

Os ambientes virtuais de aprendizagem são desenvolvidos para apoiar atividades de ensino e treinamento, porém, não foram preparados para suportar a Pedagogia de Projetos de Aprendizagem. $\mathrm{O}$ ambiente proposto neste artigo busca o desenvolvimento cooperativo e a construção de produtos interativos, tendo sempre em vista a comunicação e interação entre os usuários do ambiente. Nesse ambiente, os usuários poderão construir seus projetos e discutir suas idéias, tanto com outros usuários do ambiente, quanto com qualquer pessoa que visite seus projetos.

Os principais módulos do ambiente são:

- Controle de usuários: para viabilizar o acesso às diversas ferramentas dentro do ambiente, os perfis dos usuários foram subdivididos em papéis, 
definindo suas permissões e acessos a ferramentas. Os papéis definidos são: Aluno Desenvolvedor; Aluno visitante; Visitante comum; Visitante Pró-ativo; Professor orientador/coordenador; Professor administrador; Pais dos alunos; e, Professores que querem aprender sobre projetos. $\mathrm{O}$ cadastro dos usuários com papéis de visitante é livre, porém, o cadastro dos demais papéis deve ser feito pelo professor administrador.

- Controle de Projetos: os Alunos Desenvolvedores e Professores orientador/coordenador poderão cadastrar novos projetos e apenas o aluno desenvolvedor poderá publicar os projetos por eles desenvolvidos.

- Acompanhamento e Avaliação dos projetos: o acompanhamento dos projetos desenvolvidos é feito pelo professor orientador/coordenador designado para acompanhar o projeto específico.

- Desenvolvimento dos Projetos (Construção do Site): os projetos de aprendizagem, que são o foco do ambiente, são produzidos pelos alunos desenvolvedores, que a partir de uma questão de investigação, iniciam o desenvolvimento de seus projetos de forma cooperativa. Os resultados destes projetos desenvolvidos podem ser: um site do projeto, onde os visitantes podem comentar e fazer suas críticas; ou até mesmo um mapa conceitual, onde os usuários podem fazer relações entre os conceitos aprendidos.

- Ferramentas de interação: ajudam no desenvolvimento do processo cognitivo dos alunos e dos demais usuários do ambiente. Podemos citar, dentre elas: diário do projeto, webpapo, bilhetes nos projetos, fóruns e enquetes.

- Ferramentas que auxiliam na construção do conhecimento: os usuários do ambiente necessitam de um local onde eles possam organizar informações dispersas e também colocar suas idéias e opiniões, tais como: organizador de textos, diário do professor e diário do aluno.

\section{Arquitetura Proposta}

A arquitetura proposta segue o modelo cliente/servidor de aplicações Web, onde o cliente conversa com o servidor através de um browser, como mostrada na Figura 2. $\mathrm{O}$ browser, no lado do cliente, é o responsável por todas as interações do usuário (cliente) com o ambiente (servidor Web).

O browser, no lado do cliente, é o responsável por todas as interações do usuário (cliente) com o ambiente (servidor Web). Ao interagir com o ambiente, o usuário poderá utilizar as ferramentas disponíveis pra ele, tais como: construção/edição de sites, visualização dos sites construídos, acompanhamento dos projetos através das versões dos sites construídos e outros.

O browser do cliente envia uma solicitação ao servidor Web usando o protocolo HTTP e obtém as páginas Web para interagir no ambiente. As páginas solicitadas retornam do servidor com os programas nelas contidos.

No lado do servidor, há um servidor Web que responde as solicitações dos clientes, enviando-lhes páginas Web. As páginas Web, geralmente, são geradas pelo servidor de aplicação, caso necessite de algum processamento, caso não precise de processamento essas páginas são apenas texto HTML. O servidor de aplicação acessa os 
dados do sistema de banco de dados e o sistema de arquivos, para gerar as páginas e também para armazenar as criações e alterações feitas no ambiente e nas ferramentas.

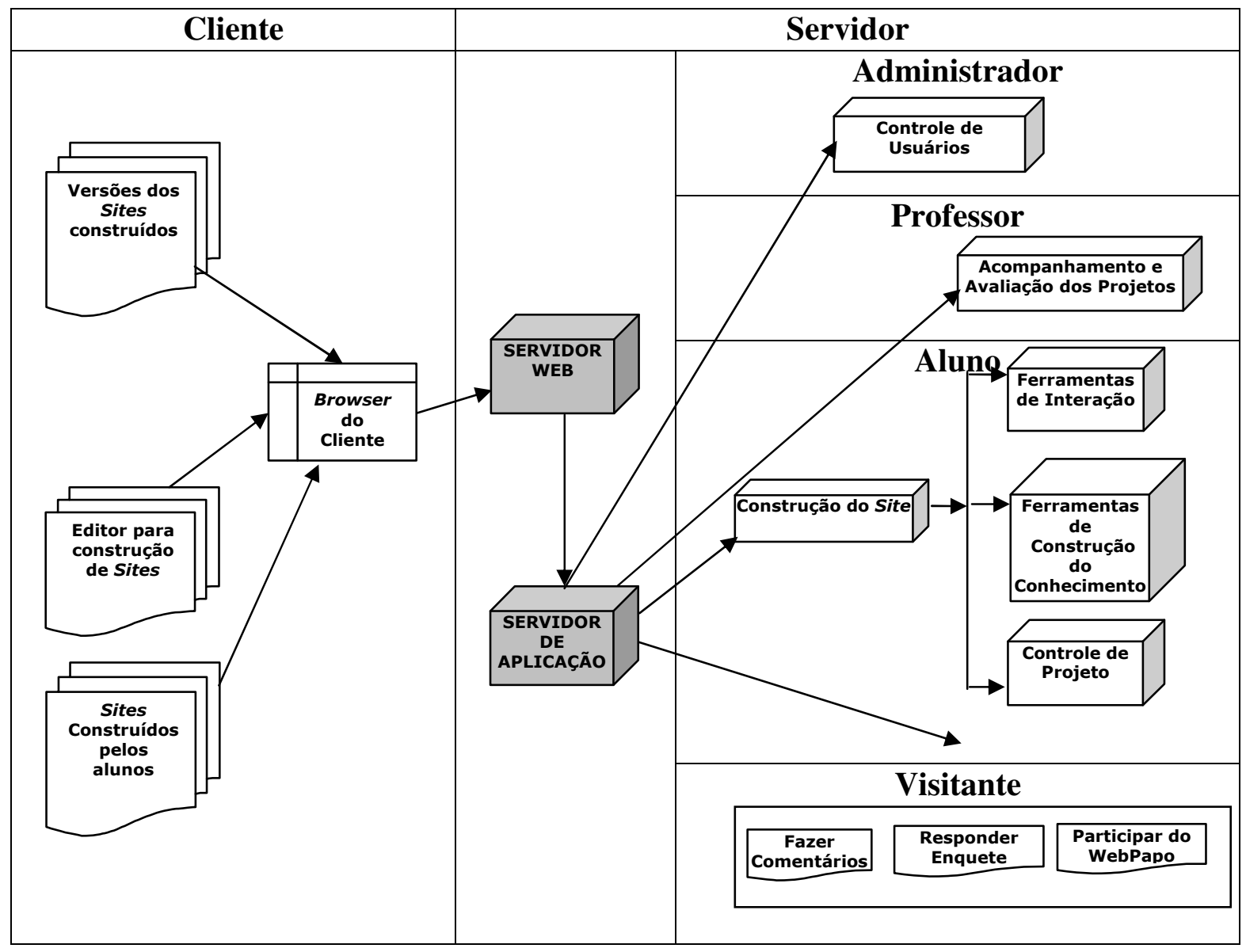

Figura 2. Arquitetura do ambiente proposto.

\section{Uma implementação para o ambiente proposto}

A implementação do ambientes proposto, Figura 3, busca integrar as informações disponíveis no ambiente, apresentando-as de forma mais organizada a seus usuários. Para integrar essas informações estão sendo desenvolvidas as ferramentas: Editor de Sites Cooperativos, Bilhetes e Controle e acompanhamento de versões dos projetos.

O Editor de sites cooperativos, mostrado na Figura 4 é uma ferramenta que auxiliará na construção dos projetos de aprendizagem. A construção dos sites pode ser feita de forma cooperativa, por usuários dispersos geograficamente. Além da possibilidade de construção interativa, os sites desenvolvidos permitem a comunicação com os visitantes dos projetos publicados. 
O editor de sites cooperativo assemelha-se aos editores de páginas Web. A edição de um site deve permitir ao aluno: escrever seu texto, abrir e salvar páginas, configurar as propriedades do texto (já implementadas) e outras funcionalidades que ainda serão implementadas, como inserir links e inserir figuras, entre outras. Além dessas, o editor proposto possuirá outras praticidades, tais como: a criação cooperativa de páginas, via Web, a verificação de persistência dos links, a inserção de ferramentas interativas (webpapo, enquete e forúm) nas páginas, além da geração de versões dos sites desenvolvidos nos projetos.

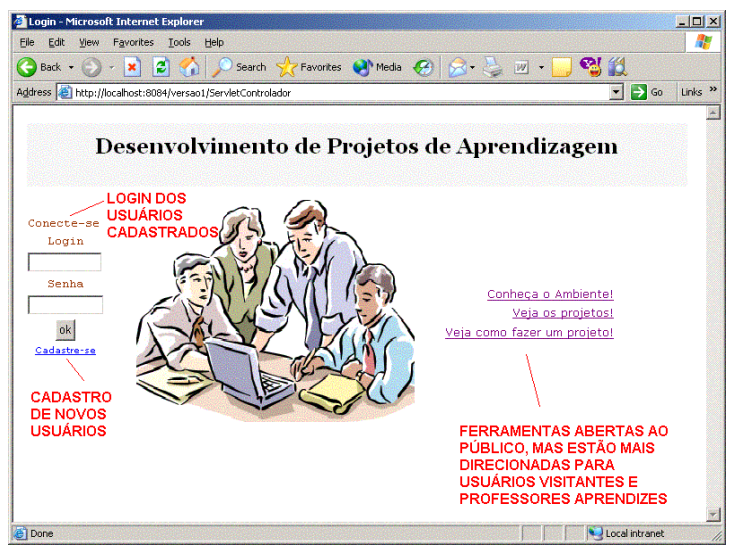

Figura 3. Ambiente de Desenvolvimento de Projetos de Aprendizagem.

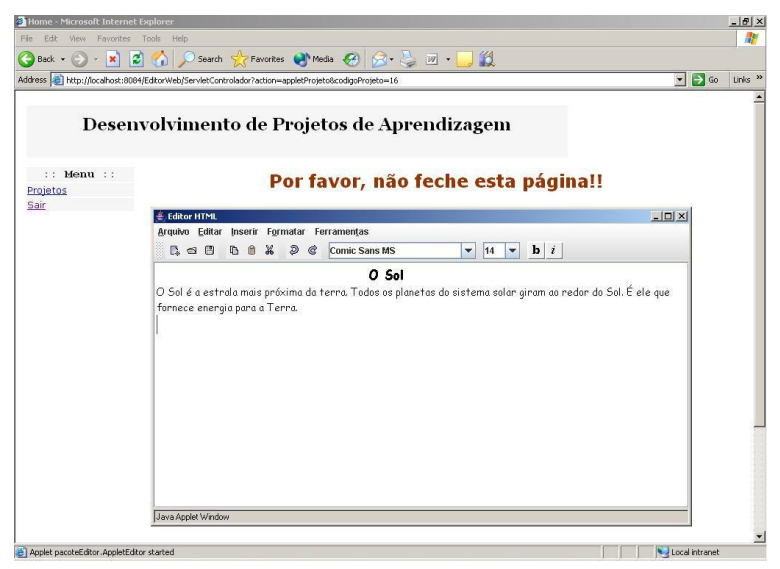

Figura 4. Editor de Sites Cooperativo.

O ciclo de desenvolvimento de um site segue a seguinte dinâmica: criação do projeto, criação do site, publicação do site e acompanhamento do professor orientador. Até o momento, a estrutura de criação do projeto já está desenvolvida e a criação dos sites está em fase de andamento.

O acompanhamento dos projetos, por parte do professor, pode ser feito através de "bilhetes", que funcionam como avisos dentro do ambiente, para que o aluno possa complementar seu projeto, como na Figura 5. Os bilhetes podem ser deixados tanto pelo professor quanto pelo aluno.

Outra forma de acompanhamento constitui-se em comentários das versões geradas do projeto, como pode ser visto na Figura 6. As versões auxiliam os professores e alunos no acompanhamento das aprendizagens, mediante o registro das suas ações no desenvolvimento do projeto. 


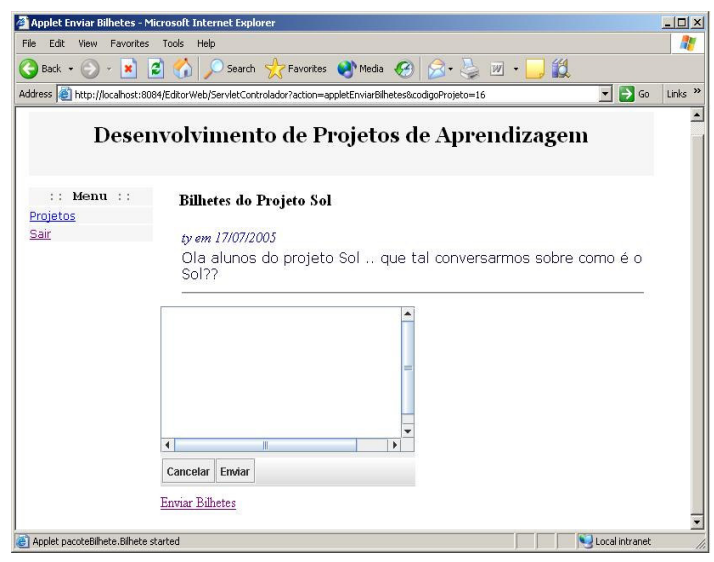

Figura 5. Bilhetes deixados no ambiente, para a interação entre os usuários.

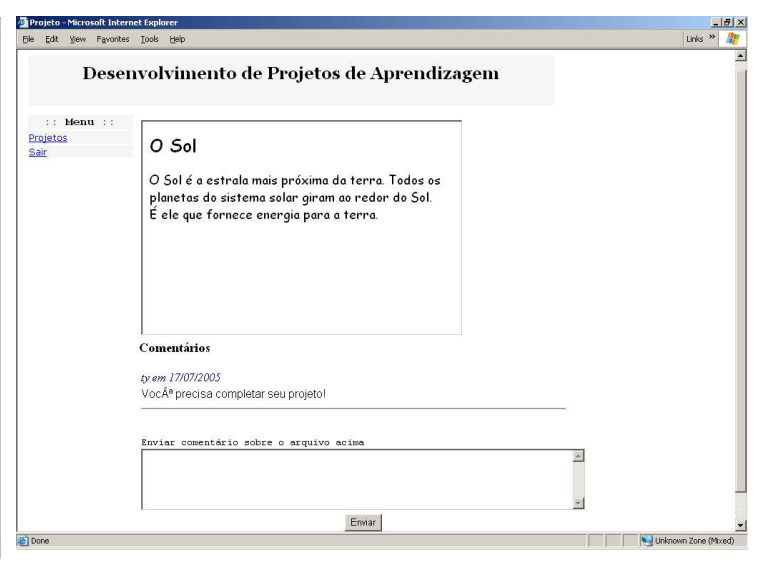

Figura 6. Versão do projeto com comentários feito pelo professor.

No desenvolvimento deste ambiente as ferramentas e linguagens que estão sendo utilizadas são: Eclipse 3.0, Linguagem Java Jdk1.4.9 e Java Servlet Pages - JSP, com gerenciador de banco de dados o MySql Administrator 4.0.20.

\section{Considerações Finais}

O desenvolvimento de projetos de aprendizagem é uma proposta inovadora de construção do conhecimento, que vem sendo implantada em escolas do ensino fundamental da rede pública, e difundida principalmente em cursos de especialização e aperfeiçoamento em Informática na Educação, promovidos pelo PROINFO (Programa Nacional de Informática na Educação). Apesar da proposta estar bem difundida ainda não se dispõe de ferramentas que apresentem uma contribuição significativa para que a prática seja estendida.

Atualmente, estamos desenvolvendo ferramentas que dêem suporte a construção desses projetos, com o patrocínio do edital FINEP para software livre. Neste contexto estamos desenvolvendo ferramentas tais como: Ambientes Virtuais, construção de mapas conceituais com suporte à avaliação, organizador de informações e a proposta do trabalho apresentado neste artigo, um ambiente para a construção cooperativa e o acompanhamento de sites interativos.

A integração dessas ferramentas que estão sendo desenvolvidas com outras que auxiliem na interação, tais como: diários de projeto, bilhetes, fóruns e enquetes possibilitará aos usuários construírem seu conhecimento e acessar suas lições aprendidas e relembrando decisões. Além de, possibilitar ao professor acompanhar os projetos desenvolvidos e contribuir para que os desenvolvedores dos projetos fiquem mais motivados.

\section{Referências Bibliográficas}

Fagundes, L., Maçada, D., Sato, L.; Aprendizes do Futuro, as Inovações Começaram. MEC, 1999.

Fagundes, Lea; Basso, Marcus; Nevado, Rosane; Bitencourt, Juliano; Menezes, Crediné. AMADIS Um Ambiente Virtual para apoio ao Desenvolvimento de

Projetos de Aprendizagem. SBIE2005, Juiz de Fora - MG, 2005. 
Grando, Anita; Konrath, Mary Lúcia P., Tarouco, Liane. Alfabetização visual para a produção de objetos Educacionais. UFRGS: Novas Tecnologias na Educação, V. $1 \mathrm{~N}^{\mathrm{o}}$ 2, Setembro, 2003.

Montisilva, Jonas; Sandia, Beatriz; Barrios, Judith. Developing Instructional Web Sites - A Software Engineering Approach. Education and Information Technologies 7:3, 201-224, 2002.

Fagundes, Lea; Basso, Marcus; Nevado, Rosane; Bitencourt, Juliano; Menezes, Crediné. Projetos de Aprendizagem - Uma experiência mediada por ambientes Telemáticos. WIE, 2005.

Carvalho, M.J. S.; Nevado, R.A., Menezes, C.S. Arquiteturas Pedagógicas para Educação a Distância: Concepções e Suporte Telemático, SBIE2005, Juiz de Fora - MG, 2005

Nevado, R.A. Espaços interativos de construção de Possíveis: uma nova modalidade de formação de professores. Tese de Doutorado. PGIE/UFRGS. 2001

Piaget, J A Equilibração das Estruturas Cognitivas; o problema central do conhecimento. Rio de Janeiro: Zahar Editores, 1976.

Piaget, J A Para Onde vai a Educação? Rio de Janeiro: José Olympio Editora. 1984 